\title{
Erratum
}

Silvio Guimarães*, Yukiko Kenmochi, Jean Cousty, Zenilton Patrocinio Jr., and Laurent Najman

\section{Erratum to "Hierarchizing graph-based image segmentation algorithms relying on region dissimilarity: the case of the Felzenszwalb-Huttenlocher method"}

https://doi.org/10.1515/mathm-2019-0010

Received October 21, 2019; accepted October 25, 2019

Abstract: The original version of the article was published in Mathematical Morphology - Theory and Applications 2 (2017) 55-75. Unfortunately, the original version contains a mistake: in the definition of $\operatorname{Dif}\left(C_{1}, C_{2}\right)$ in Section 3.6, max should be replaced by min. In this erratum we correct the formula defining $\operatorname{Dif}\left(C_{1}, C_{2}\right)$.

Keywords: scale set theory, quasi-flat zone hierarchy, minimum spanning tree, hierarchical image segmentation, graph-based method

The first formula in Section 3.6 in the original version of the article [1],

$$
\operatorname{Dif}\left(C_{1}, C_{2}\right)=\max \left\{w(\{x, y\}) \mid x \in V\left(C_{1}\right), y \in V\left(C_{2}\right),(x, y) \in E\right\}
$$

should be

$$
\operatorname{Dif}\left(C_{1}, C_{2}\right)=\min \left\{w(\{x, y\}) \mid x \in V\left(C_{1}\right), y \in V\left(C_{2}\right),(x, y) \in E\right\} .
$$

The rest of the article is not influenced by this replacement.

\section{References}

[1] Guimarães, S., Kenmochi, Y., Cousty, J., Patrocinio, Z., Najman, L.: Hierarchizing graph-based image segmentation algorithms relying on region dissimilarity: the case of the Felzenszwalb-Huttenlocher method. Mathematical Morphology - Theory and Applications 2, 55-75 (2017). 10.1515/mathm-2017-0004

\footnotetext{
`Corresponding Author: Silvio Guimarães: PUC Minas - ICEI - DCC - VIPLAB, E-mail: sjamil@pucminas.br Yukiko Kenmochi, Jean Cousty, Laurent Najman: Université Paris-Est, LIGM (UMR 8049), CNRS - ENPC - ESIEE Paris - UPEM, E-mail: \{yukiko.kenmochi, jean.cousty, laurent.najmain\}@esiee.fr

Zenilton Patrocinio Jr.: PUC Minas - ICEI - DCC - VIPLAB, E-mail: zenilton@pucminas.br
} 